\title{
Caldo de cana desidratado na ração de codornas de corte
}

\author{
Renato Andrade dos Santos ${ }^{(1)}$, Elisanie Neiva Magalhães Teixeira(1), Janete Gouveia de Souza(1), \\ José Aparecido Moreira(1), Alex Martins Varela de Arruda ${ }^{(2)}$, \\ Roseane Madeira Bezerra( ${ }^{(3)}$ e Cláudia de Castro Goulart( ${ }^{(4)}$
}

\begin{abstract}
(1)Universidade Federal do Rio Grande do Norte, Departamento de Produção Animal, RN 106, Km 03, Distrito de Jundiaí, CEP $59280-000$ Macaíba, RN, Brasil. E-mail: renatoandrsantos@hotmail.com, elisanieteixeira@yahoo.com.br, jnobre5@hotmail.com, japmoreira@bol.com.br (2)Universidade Federal Rural do Semi-Árido, Departamento de Ciências Animais, BR 110, Km 47, Presidente Costa, CEP 59625-900 Mossoró, RN, Brasil. E-mail: alexmva@ufersa.edu.br ${ }^{(3)}$ Universidade Federal da Paraíba, Departamento de Zootecnia, Rodovia PB-079, Km 12, CEP 58397-000 Areia, PB, Brasil. E-mail: roseanemadeira@hotmail.com (4)Universidade Estadual do Vale do Acaraú, Departamento de Zootecnia, Avenida da Universidade, no 850, Betânia, CEP 62040-370 Sobral, CE, Brasil. E-mail: clcgoulart@hotmail.com
\end{abstract}

Resumo - O objetivo deste trabalho foi avaliar o efeito do caldo de cana desidratado (CCD) no desempenho, na qualidade de carcaça e no índice econômico de codornas (Coturnix coturnix) europeias, no período de 22 a 42 dias de idade. Foram utilizadas 192 codornas de corte com 22 dias de idade, distribuídas em delineamento inteiramente casualizado, com quatro tratamentos e seis repetições de oito aves. Foram adicionados $0,1,5,3,0$ e 4,5\% de CCD na ração. Avaliou-se a viabilidade econômica da inclusão dos níveis de CCD nas rações por meio da margem bruta relativa das dietas. No período de 29 a 35 dias de idade, houve efeito linear crescente para o consumo de ração com o aumento de CCD na ração. No entanto, houve efeito quadrático dos níveis de CCD sobre o peso da carcaça, da coxa + sobrecoxa e da gordura abdominal, e os níveis ótimos estimados foram de 1,69, 2,50 e 2,34\%, respectivamente. Houve efeito linear decrescente dos níveis de CCD sobre o peso de peito com e sem pele. A análise econômica indicou maior lucro ao produtor com uso da ração convencional. Entretanto, entre os níveis de inclusão de $\mathrm{CCD}$, o de $1,5 \%$ apresentou os melhores resultados, com uma diferença de $0,47 \%$ na margem de lucro em relação à ração convencional. A adição de 1,69 e 2,50\% de caldo de cana desidratado na ração é recomendada para atingir maior peso de carcaça e coxa + sobrecoxa em codornas de corte, respectivamente.

Termos para indexação: Coturnix coturnix, Saccharum officinarum, alimento alternativo, cana-de-açúcar.

\section{Dehydrated cane juice in meat quail feed}

\begin{abstract}
The objective of this work was to evaluate the effect of dehydrated cane juice (DCJ) on the performance, carcass quality, and economic index of European quails (Coturnix coturnix), during the period from 22 to 42 days of age. One hundred and ninety-two quails with 22 days of age were distributed in a completely randomized design, with four treatments and six replicates of eight birds each. DCJ was added at $0,1.5,3.0$, and $4.5 \%$ in the feed. The economic feasibility of including DCJ levels in the feed was evaluated through relative gross margin. In the period from 29 to 35 days of age, there was increased linear effect of feed intake with the increase of DCJ in the feed. However, there was a quadratic effect of DCJ levels on carcass, drumstick+thigh, and abdominal fat weights, and the estimated optimum levels were 1.69, 2.50, and $2.34 \%$, respectively. There was a decreasing linear effect of DCJ levels on breast weight with and without skin. Economic analysis showed higher profits to the producer with the use of conventional feed. However, among the DCJ levels of inclusion, the level of $1.5 \%$ showed the best results, with a difference of $0.47 \%$ in relative gross margin when compared to the conventional feed. The addition of 1.69 and $2.50 \%$ of dehydrated cane juice in the feed is recommended to achieve higher carcass and drumstick+thigh weights in meat quails, respectively.
\end{abstract}

Index terms: Coturnix coturnix, Saccharum officinarum, alternative feed, sugar cane.

\section{Introdução}

Na produção de aves, os gastos com a alimentação correspondem a cerca de $75 \%$ do custo total. Entre os fatores limitantes para o desenvolvimento da avicultura, estão a baixa disponibilidade, em algumas regiões do Brasil, de grãos para as rações, bem como o alto custo do principal ingrediente, o milho (Zea mays L.), que fica mais caro em períodos de entressafra (Cordeiro et al., 2003). Neste contexto, estão sendo realizados 
estudos com alimentos alternativos, especialmente os energéticos, para substituir total ou parcialmente esse cereal (Cordeiro et al., 2003).

A cana-de-açúcar (Saccharum officinarum L.) é um dos alimentos que apresenta alto teor energético na sua composição. De acordo com Rostagno (2011), o açúcar do caldo de cana fornece maior quantidade de energia (3.831 kcal kg-1 de energia metabolizável) do que o milho (3.371 kcal kg-1 de energia metabolizável). Além disso, dependendo da época do ano, o caldo de cana pode atingir preços inferiores ao do milho, o que viabiliza sua utilização nas rações (Companhia Nacional de Abastecimento, 2013; União da Indústria de Cana-de-Açúcar, 2013).

Teixeira et al. (2005) concluíram, a partir dos valores de energia metabolizável do milho e do caldo de cana, que são necessários cerca de $6,0 \mathrm{~L}$ de caldo de cana desidratado para substituir 1,0 kg de milho, ou seja, para cada $10 \mathrm{~g}$ de milho retirados da ração, deve-se disponibilizar em torno de $60 \mathrm{~g}$ do caldo de cana para a codorna. Este resultado está de acordo com o valor de aproximadamente 5,0 L de caldo de cana desidratado usado para substituir 1,0 $\mathrm{kg}$ de milho para suínos (Rostagno, 2011).

O objetivo deste trabalho foi avaliar o efeito do caldo de cana desidratado no desempenho, na qualidade de carcaça e no índice econômico de codornas europeias (Coturnix coturnix), no período de 22 a 42 dias de idade.

\section{Material e Métodos}

O projeto foi avaliado pela Comissão de Ética no Uso de Animais (CEUA) da Universidade Federal do Rio Grande do Norte (UFRN); contudo, foi isento da aprovação do comitê para execução, de acordo com a Lei n¹1.794/2008 (Brasil, 2008), uma vez que a intervenção não experimental relacionada às práticas agropecuárias não foi considerada como experimentação.

As temperaturas médias mínima e máxima aferidas durante o experimento, no período da manhã e da tarde, foram de $28,1-27^{\circ} \mathrm{C}$ e de $30,5-29,3^{\circ} \mathrm{C}$, respectivamente. O experimento foi conduzido no município de Macaíba, no Rio Grande do Norte, de 3 a 23 de novembro de 2013. Foram utilizadas 192 codornas de corte (Coturnix coturnix coturnix), machos e fêmeas, com 22 dias de idade e peso médio inicial de $145 \mathrm{~g}$, distribuídas em delineamento inteiramente casualizado, com quatro tratamentos e seis repetições de oito aves.

De 1 a 21 dias, as codornas receberam ração balanceada de acordo com sua idade e foram alojadas em galpão com piso de cimento com cama de maravalha de madeira, com comedouros tubulares e bebedouros pendulares. Aos 22 dias, as codornas foram distribuídas pelo peso médio e alojadas em galpão com boxes de 1,40x1,80 m, com maravalha de madeira, comedouros tubulares e bebedouros pendulares; foi adotado um programa de iluminação contínuo, com 24 horas de luz (natural + artificial).

A cana-de-açúcar utilizada no experimento foi da variedade Caiana, plantada em solo predominante do tipo Latossolo Vermelho-Amarelo, sem irrigação. A planta foi cortada manualmente em idades aleatórias, e o caldo foi extraído em moedor elétrico, coado e armazenado em garrafas de plástico a $6-7^{\circ} \mathrm{C}$, por aproximadamente 24 horas.

Para o procedimento de secagem do caldo, foram adicionados, em batedeiras, por $40 \mathrm{~min}: 1,750 \mathrm{~L}$ de caldo de cana; $35 \mathrm{~g}$ de emulsificante Portogel (Du Porto Indústria Alimentícia, Ltda., Porto Feliz, SP), cujos ingredientes foram água, propileno glicol e emulsificantes; e $35 \mathrm{~g}$ do espessante liga neutra $\mathrm{Du}$ Porto (Du Porto Indústria Alimentícia, Ltda., Porto Feliz, SP), cujos ingredientes foram açúcar e os espessantes goma guar e carboximetilcelulose. O emulsificante para cada porção de $10 \mathrm{~g}$ apresentava, em sua composição, $24 \mathrm{kcal}$ de energia, $1,1 \mathrm{~g}$ de carboidratos, 2,1 $\mathrm{g}$ de gordura total e 2,0 $\mathrm{g}$ de gordura saturada; já o estabilizante, para cada porção de $10 \mathrm{~g}$, apresentava, em sua composição, $34 \mathrm{kcal}$ de energia, $8,5 \mathrm{~g}$ de carboidratos, $0,9 \mathrm{~g}$ de fibra alimentar e $30 \mathrm{mg}$ de sódio.

Em seguida, $250 \mathrm{~mL}$ do produto batido foram distribuídos em bandejas de aço inox e alocados para secar em secador a gás, a $60^{\circ} \mathrm{C}$, por 16 horas, de acordo com a metodologia de Marques (2009). O rendimento médio foi de $16 \%$ de caldo de cana desidratado.

A análise físico-química do caldo de cana desidratado foi realizada no Núcleo de Processamento Primário e Reuso de Água Produzida e Resíduo da UFRN, localizado em Natal, RN. Os teores, em $\mathrm{Mg} \mathrm{L}^{-1}$, dos minerais foram: 31,760 de cálcio; 0,247 de cobre; 8,197 de ferro; 14,550 de fósforo total; 30,250 de magnésio; 1,294 de manganês; 438,500 de potássio; 16,350 de sódio; e 1,585 de zinco total. 
O primeiro tratamento foi constituído de uma ração convencional, à base de milho e farelo de soja. Os outros tratamentos consistiram de rações com níveis de inclusão de 1,5, 3,0 e 4,5\% de caldo de cana desidratado na ração. As rações foram formuladas para atender às exigências nutricionais das codornas de corte, seguindo as recomendações de Silva \& Costa (2009). A energia metabolizável aparente e o teor de proteína do caldo de cana foram determinados como em Teixeira et al. (2005) (Tabela 1). Já a composição química do caldo de cana desidratado e das dietas com diferentes níveis de caldo de cana desidratado $(0,1,5$, 3,0 e 4,4\%), para codornas europeias de 22 a 42 dias de idade, foi determinada de acordo com Silva (1998) (Tabela 2).

Tabela 1. Composição percentual e calculada das rações experimentais, com base na matéria natural, para codornas de corte de 22 a 42 dias de idade.

\begin{tabular}{lcccc}
\hline Ingredientes (\%) & \multicolumn{4}{c}{ Níveis de caldo de cana desidratado } \\
\cline { 2 - 5 } & $0 \%$ & $1,5 \%$ & $3,0 \%$ & $4,5 \%$ \\
\hline Milho & 58,788 & 57,493 & 56,199 & 54,900 \\
Farelo de soja & 36,104 & 36,281 & 36,457 & 36,630 \\
Caldo de cana & 0,000 & 1,500 & 3,000 & 4,500 \\
Óleo de soja & 2,121 & 1,737 & 1,354 & 0,970 \\
Fosfato bicálcico & 0,997 & 1,001 & 1,005 & 1,010 \\
Calcário & 0,833 & 0,830 & 0,827 & 0,820 \\
DL-metionina & 0,368 & 0,371 & 0,373 & 0,380 \\
Sal comum & 0,271 & 0,272 & 0,273 & 0,270 \\
L-lisina HCL & 0,318 & 0,316 & 0,314 & 0,310 \\
Suplemento mineral ${ }^{(1)}$ & 0,100 & 0,100 & 0,100 & 0,100 \\
Suplemento vitamínico ${ }^{(2)}$ & 0,100 & 0,100 & 0,100 & 0,100 \\
\hline Total & 100,000 & 100,000 & 100,000 & 100,000 \\
\hline Composição nutricional $(\%)$ & & & & \\
Energia metabolizável $\left(\mathrm{kcal}^{\mathrm{k}} \mathrm{kg}^{-1}\right)$ & 3.050 & 3.050 & 3.050 & 3.050 \\
Proteína bruta & 22,00 & 22,00 & 22,00 & 22,00 \\
Cálcio & 0,70 & 0,70 & 0,70 & 0,70 \\
Sódio & 0,15 & 0,15 & 0,15 & 0,15 \\
Fósforo disponível & 0,30 & 0,30 & 0,30 & 0,30 \\
Lisina total & 1,40 & 1,40 & 1,40 & 1,40 \\
Metionina total & 0,69 & 0,70 & 0,70 & 0,70 \\
Metionina+cistina total & 1,04 & 1,04 & 1,04 & 1,04 \\
Treonina total & 0,83 & 0,84 & 0,84 & 0,83 \\
\hline
\end{tabular}

${ }^{(1)}$ De acordo com as recomendações nutricionais de Silva \& Costa (2009). Composição básica do produto: sulfato de ferro, sulfato de cobre, óxido de zinco, monóxido de manganês, selenito de sódio, iodeto de cálcio e veículo q.s.p. Níveis de garantia por $\mathrm{kg}$ do produto: $140.000 \mathrm{mg}$ de manganês; $120.000 \mathrm{mg}$ de zinco; $100.000 \mathrm{mg}$ de ferro; $18.000 \mathrm{mg}$ de cobre; $2.000 \mathrm{mg}$ de iodo; e $600 \mathrm{mg}$ de selênio. ${ }^{(2)}$ Níveis de garantia por $\mathrm{kg}$ do produto: 40.000.000 UI de vitamina A; 10.000.000 UI de vitamina D3; 80.000 UI de vitamina E; $10.000 \mathrm{mg}$ de vitamina K3; $64.000 \mathrm{mg}$ de vitamina B12; $7.200 \mathrm{mg}$ de vitamina B1; $24.000 \mathrm{mg}$ de vitamina B2; $11.200 \mathrm{mg}$ de vitamina B6; $4.000 \mathrm{mg}$ de ácido fólico; $48.000 \mathrm{mg}$ de ácido pantotênico; $160.000 \mathrm{mg}$ de ácido nicotínico; e $260 \mathrm{mg}$ de biotina.
As variáveis avaliadas foram: consumo de ração (grama por ave), peso final (grama por ave), ganho de peso (grama por ave), conversão alimentar $\left(\mathrm{g} \mathrm{g}^{-1}\right)$, peso de carcaça $(\mathrm{g})$, peso de peito com e sem pele $(\mathrm{g})$, peso de coxa e sobrecoxa (g), peso da gordura abdominal (g), custo da alimentação ( $\mathrm{R} \$$ por tratamento), peso da codorna produzida (quilograma por tratamento), custo da codorna produzida $\left(\mathrm{R} \$ \mathrm{~kg}^{-1}\right)$, renda bruta $(\mathrm{R} \$)$, margem bruta ( $\mathrm{R} \$)$ e margem bruta relativa (\%).

$\mathrm{O}$ consumo de ração foi calculado pela diferença entre a quantidade de ração fornecida e as sobras, pesadas no início e no final de cada fase experimental. O peso final foi obtido pelo peso total dividido pelo número de aves. Para a determinação do ganho de peso, as aves também foram pesadas no início e no final de cada período experimental, aos 28,35 e 42 dias de idade, respectivamente. A partir dos dados de consumo de ração e ganho de peso, foi calculada a conversão alimentar dos animais em cada período.

Aos 42 dias, foram selecionadas duas aves por parcela de acordo com o peso médio, para realização do abate por deslocamento cervical e posterior sangria, após jejum de 12 horas. No abate, foi aferido o peso vivo, o peso da carcaça, o peso dos cortes nobres (peito, coxa e sobrecoxa) e a gordura abdominal, tendo-se considerado o peso da carcaça eviscerada (cabeça, pescoço e pés) em relação ao peso vivo.

Tabela 2. Composição química do caldo de cana desidratado (CCD) e das rações formuladas.

\begin{tabular}{lccccc}
\hline Nutrientes (\%) & CCD & \multicolumn{4}{c}{ Ração com CCD (\%) } \\
\cline { 3 - 6 } & & 0 & 1,5 & 3,0 & 4,5 \\
\hline Matéria seca & 89,25 & 90,87 & 93,82 & 89,15 & 89,30 \\
Água & 10,75 & 9,13 & 6,18 & 10,85 & 10,70 \\
Matéria mineral & 5,44 & 6,72 & 6,74 & 5,11 & 5,80 \\
Matéria orgânica & 94,56 & 93,28 & 93,26 & 94,89 & 94,20 \\
Proteína bruta & 0,62 & 26,26 & 24,83 & 24,51 & 24,60 \\
Extrato etéreo & 2,04 & 2,10 & 1,61 & 2,59 & 2,24 \\
Carboidratos & 68,43 & 66,12 & 66,15 & 70,19 & 68,53 \\
FDN & 15,67 & 15,18 & 11,98 & 16,78 & 17,25 \\
FDA & 5,90 & 4,32 & 4,37 & 5,01 & 6,73 \\
Hemicelulose & 9,78 & 10,85 & 7,60 & 11,77 & 10,52 \\
CNF & 52,76 & 50,94 & 54,17 & 53,41 & 51,28 \\
Lignina & 1,82 & 1,61 & 0,81 & 1,12 & 1,68 \\
Celulose & 4,08 & 2,71 & 3,56 & 3,89 & 5,06 \\
Energia bruta & 3.692 & 4.162 & 3.724 & 3.812 & 3.683 \\
\hline
\end{tabular}

(1)FDN, fibra em detergente neutro; FDA, fibra em detergente ácido; e CNF, carboidratos não fibrosos. 
Avaliou-se a viabilidade econômica da inclusão dos níveis de caldo de cana desidratado nas rações de codorna de corte com uso da metodologia de Guidoni (1994), por meio da margem bruta relativa das dietas. Para a determinação da margem bruta relativa, foram considerados somente os custos variáveis de alimentação, uma vez que os custos fixos foram iguais para todos os tratamentos. Para esses cálculos, foram considerados o consumo de ração e o peso da carcaça durante o período experimental.

A partir dos preços dos produtos (Tabela 3), foram calculados os custos por quilograma de cada ração experimental. Em seguida, multiplicou-se esse valor pelo consumo de ração dos animais (quilograma por ave) durante o período avaliado, para obter o custo da alimentação, o qual foi dividido pelo peso da carcaça $(\mathrm{kg})$. A renda bruta foi calculada por meio da multiplicação da produção de codornas no período pelo preço do quilograma da ave. A margem bruta de cada tratamento foi calculada pela diferença entre a renda bruta e o custo da alimentação.

As análises estatísticas foram realizadas com uso do programa SAS (SAS Institute, Cary, NC, EUA). Os dados foram submetidos à análise de regressão, tendo-se relacionado os dados obtidos dentro de cada variável aos níveis de inclusão do caldo de cana desidratado. Também foram aplicados os testes de homocedasticidade de Bartlett, Levene e Brow \& Forsythe.

Tabela 3. Preços dos produtos utilizados nas rações experimentais e da carne de codorna.

\begin{tabular}{|c|c|}
\hline Produtos & Preços $\left(\mathrm{R} \$ \mathrm{~kg}^{-1}\right)$ \\
\hline Milho(1) $^{(1)}$ & 0,35 \\
\hline Soja $a^{(1)}$ & 0,42 \\
\hline Caldo de cana ${ }^{(1)}$ & 1,95 \\
\hline Óleo de soja ${ }^{(2)}$ & 2,50 \\
\hline Fosfato bicálcico ${ }^{(2)}$ & 1,70 \\
\hline Calcário(2) $^{(2)}$ & 0,20 \\
\hline DL-metionina $^{(2)}$ & 9,02 \\
\hline L-lisina $\mathrm{HCL}^{(2)}$ & 13,11 \\
\hline Sal comum ${ }^{(2)}$ & 0,27 \\
\hline Suplemento mineral ${ }^{(2)}$ & 3,90 \\
\hline Suplemento vitamínico ${ }^{(2)}$ & 14,48 \\
\hline Emulsificante Portogel $^{(1)}$ & 9,65 \\
\hline Estabilizante liga neutra Du Port ${ }^{(1)}$ & 8,63 \\
\hline Codorna abatida ${ }^{(1)}$ & 18,61 \\
\hline
\end{tabular}

(1)Valores obtidos no mercado local de Natal, RN. (2)Estimativa de preço da Guaraves Alimentos Ltda. (Guarabira, PB).

\section{Resultados e Discussão}

Os testes de Bartlett, Levene e Brow \& Forsythe indicaram homogeneidade de variâncias.

$\mathrm{O}$ aumento dos níveis de caldo de cana desidratado na ração até 4,5\% não promoveu efeito nos parâmetros de desempenho avaliados em todos os períodos, o que mostra que a codorna de corte conseguiu aproveitar a energia e os nutrientes oferecidos na ração de forma adequada, sem prejuízos ao seu desempenho, que foi satisfatório à sua idade (Tabela 4). Esse resultado difere do observado por Cabral (2006) que, ao avaliar frangos de corte de 1 a 21 dias de idade alimentados com rações isoproteicas e isocalóricas, relatou aumento no ganho de peso e redução na conversão alimentar quando se aumentou o fornecimento de "mel seco" de cana, em substituição parcial ao milho. Segundo o autor, o mel seco de cana fornece um tipo de energia que é rapidamente metabolizada pelo organismo das aves, mas que não é aproveitada integralmente pelo corpo do animal, o que ocasiona um descompasso entre a fonte de energia e a proteína, com consequente redução na eficiência alimentar, à medida que se elevam os níveis de mel seco de cana na ração (Cabral, 2006).

Houve efeito quadrático dos níveis de caldo de cana desidratado sobre o peso da carcaça $\left(y=173,71+4,2767 x-1,2644 x^{2} ; R^{2}=0,99\right), d a$ coxa + sobrecoxa $\left(y=36,055+1,1263 x-0,2256 x^{2}\right.$; $\left.\mathrm{R}^{2}=0,91\right)$ e da gordura abdominal $(\mathrm{y}=3,3295-$ $\left.0,8903 x+0,19 x^{2} ; R^{2}=0,97\right)$, em que os níveis ótimos estimados foram de $1,69,2,50$ e $2,34 \%$ de caldo de cana desidratado, respectivamente (Tabela 5). No entanto, houve efeito linear decrescente dos níveis de caldo de cana desidratado sobre o peso de peito com $\left(\mathrm{y}=66,267-0,5653 \mathrm{x} ; \mathrm{R}^{2}=0,83\right)$ e sem pele $\left(y=60,286-0,7193 x ; R^{2}=0,58\right)$.

No presente trabalho, não foi observado efeito significativo dos níveis de caldo de cana desidratado para peso final aos 42 dias; entretanto, houve efeito quadrático para peso de carcaça. Cordeiro et al. (2003), ao utilizar níveis crescentes de açúcar de cana como fonte de energia para frangos de corte de até 21 dias de idade, também não encontraram diferenças significativas quanto ao peso de peito. É possível que isso tenha ocorrido em razão da diferença do peso das vísceras e da gordura abdominal, uma vez que se constatou maior peso de gordura das aves alimentadas com a ração convencional do que com a ração com $1,5 \%$ de caldo de cana desidratado. 
No presente trabalho, à medida que se aumentaram os níveis de inclusão de caldo de cana desidratado nas rações, diminuiu o peso de peito com e sem pele. É provável que a metabolização da sacarose tenha proporcionado um deficit de energia, o que promoveu um desbalanceamento entre a energia na forma de sacarose, rapidamente metabolizada, e a proteína da ração. Conforme Ton et al. (2011), a carência ou o desbalanceamento entre os nutrientes pode reduzir a síntese proteica. Longo et al. (2005), contudo, não verificaram efeito de fontes de carboidratos (milho, amido de mandioca, glúten de milho, plasma sanguíneo e sacarose) sobre o rendimento de coxa e sobrecoxa de frangos de corte abatidos aos 42 dias de idade.

No presente trabalho, o peso da gordura abdominal apresentou efeito quadrático com o aumento dos níveis de caldo de cana desidratado na ração das codornas europeias abatidas aos 42 dias de idade, e o menor peso de gordura $(2,287 \mathrm{~g})$ foi obtido com o nível de $2,3 \%$ de caldo de cana desidratado $\left(y=3,3295-0,8903 x+0,19 x^{2} ; R^{2}=0,97\right)$.

Segundo Ton et al. (2011), o aumento da gordura abdominal está associado ao excesso de energia metabolizável na ração e à alta relação energia:proteína, o que faz com que o excesso de energia seja armazenado pelas codornas na forma de gordura. À medida que os níveis de energia metabolizável da ração foram elevados, a percentagem de gordura abdominal também aumentou. De acordo com Mendonça et al. (2007), a energia alimentar em excesso se relaciona à deposição de lipídios, na maioria dos animais.

Houve maior lucro com a utilização da ração convencional (Tabela 6). Resultado similar foi obtido por Cordeiro et al. (2003), que estudaram cinco níveis de açúcar de cana, em substituição parcial ao milho, como fonte de energia na alimentação de frangos de corte submetidos a rações isocalóricas e isoproteicas formuladas à base de milho e farelo de soja, no período de 1 a 21 dias de idade. Os autores observaram aumento linear no custo, à medida que os níveis de açúcar se elevaram, e efeito linear negativo em relação ao índice de eficiência econômica, o que mostra que, com o aumento dos níveis de açúcar utilizados, houve maior custo ou menor eficiência econômica das rações.

Cabral (2006) avaliou a inclusão de 0, 5, 10, 15, 20 e $25 \%$ de mel desidratado de cana, em substituição ao milho, em rações isoproteicas e isocalóricas para frangos de corte de 1 a 42 dias de idade. O autor constatou que, com a inclusão de $8,3 \%$ do mel desidratado de cana, houve maior retorno econômico, de $\mathrm{R} \$ 1,87$ por ave. É possível que o resultado favorável da análise econômica de Cabral (2006), com o uso de mel desidratado de cana, tenha ocorrido em razão do tempo de criação das aves submetidas ao mel desidratado, da técnica mais aprofundada utilizada pelo autor no processamento dos resultados econômicos

Tabela 4. Consumo de ração, peso final, ganho de peso e conversão alimentar nos períodos de criação de codornas europeias alimentadas com diferentes níveis de caldo de cana desidratado.

\begin{tabular}{|c|c|c|c|c|c|c|c|}
\hline \multirow[t]{2}{*}{ Caldo de cana desidratado } & \multicolumn{4}{|c|}{ Níveis de caldo de cana desidratado (\%) } & \multirow[t]{2}{*}{ Regressão } & \multirow[t]{2}{*}{$\mathrm{R}^{2}$} & \multirow{2}{*}{$\begin{array}{l}\text { CV } \\
(\%)\end{array}$} \\
\hline & 0 & 1,5 & 3,0 & 4,5 & & & \\
\hline \multicolumn{8}{|c|}{ Período de criação de 22-28 dias } \\
\hline Consumo de ração (grama por ave) & 60,35 & 61,63 & 59,11 & 61,09 & ns & 0,96 & 13,53 \\
\hline Peso final (grama por ave) & 190,72 & 189,09 & 187,85 & 186,48 & ns & 0,57 & 2,85 \\
\hline Ganho de peso (grama por ave) & 45,84 & 45,46 & 45,88 & 44,64 & ns & 0,84 & 5,96 \\
\hline Conversão alimentar $\left(\mathrm{g} \mathrm{g}^{-1}\right)$ & 1,314 & 1,358 & 1,280 & 1,374 & ns & 0,75 & 11,25 \\
\hline \multicolumn{8}{|c|}{ Período de criação de 29-35 dias } \\
\hline Consumo de ração (grama por ave) & 165,17 & 175,81 & 175,08 & 191,78 & ns & 0,56 & 9,08 \\
\hline Peso final (grama por ave) & 222,83 & 223,45 & 222,70 & 220,54 & ns & 0.93 & 3,64 \\
\hline Ganho de peso (grama por ave) & 32,11 & 34,35 & 34,85 & 34,05 & ns & 0,87 & 7,75 \\
\hline Conversão alimentar $\left(\mathrm{g} \mathrm{g}^{-1}\right)$ & 5,334 & 5,173 & 5,079 & 5,711 & ns & 0,46 & 8,47 \\
\hline \multicolumn{8}{|c|}{ Período de criação de 36-42 dias } \\
\hline Consumo de ração (grama por ave) & 192,46 & 193,07 & 190,45 & 175,19 & ns & 0,89 & 8,26 \\
\hline Peso final (grama por ave) & 255,13 & 254,75 & 247,33 & 244,23 & ns & 0,39 & 5,17 \\
\hline Ganho de peso (grama por ave) & 32,30 & 31,30 & 24,64 & 23,70 & ns & 0,52 & 10,69 \\
\hline Conversão alimentar $\left(\mathrm{g} \mathrm{g}^{-1}\right)$ & 6,371 & 6,926 & 7,862 & 8,064 & ns & 0,22 & 8,15 \\
\hline
\end{tabular}

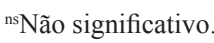


e das despesas existentes que foram diferentes das estabelecidas no presente trabalho. Cabe salientar que os preços referentes às matérias primas utilizadas nos cálculos de Cabral (2006) foram cotados no mercado de Natal, RN, e de Guarabira, PB, em abril de 2004, enquanto os do presente estudo foram cotados de dezembro de 2013 a fevereiro de 2014.

Apesar do maior lucro obtido pela ração convencional, pôde-se observar que, entre os níveis de inclusão de caldo de cana desidratado, a ração com nível de 1,5\% apresentou os melhores resultados, tendo alcançado uma diferença de apenas $0,47 \%$ na margem bruta relativa em relação à ração convencional. Dessa forma, é possível que, em situações de escassez ou preços elevados do milho em relação ao caldo de cana, haja menor diferença na margem bruta de lucro.

Tabela 5. Peso das características de carcaça e gordura abdominal de codornas europeias alimentadas com ração contendo caldo de cana desidratado (CCD), aos 42 dias de idade.

\begin{tabular}{lccccc}
\hline $\begin{array}{l}\text { CCD } \\
(\%)\end{array}$ & $\begin{array}{c}\text { Carcaça } \\
(\mathrm{g})\end{array}$ & $\begin{array}{c}\text { Peito com } \\
\text { pele }(\mathrm{g})\end{array}$ & $\begin{array}{c}\text { Peito sem } \\
\text { pele }(\mathrm{g})\end{array}$ & $\begin{array}{c}\text { Coxa e } \\
\text { sobrecoxa }(\mathrm{g})\end{array}$ & $\begin{array}{c}\text { Gordura } \\
(\mathrm{g})\end{array}$ \\
\hline 0 & 173,71 & 66,45 & 59,75 & 36,01 & 3,36 \\
1,5 & 177,28 & 65,49 & 60,66 & 37,19 & 2,32 \\
3,0 & 175,16 & 63,88 & 56,83 & 37,35 & 2,46 \\
4,5 & 167,35 & 64,16 & 57,43 & 36,50 & 3,14 \\
\hline Regressão $^{(1)}$ & $\mathrm{Q}^{* *}$ & $\mathrm{~L}^{*}$ & $\mathrm{~L}^{*}$ & $\mathrm{Q}^{*}$ & $\mathrm{Q}^{*}$ \\
$\mathrm{R}^{2}$ & 0,99 & 0,83 & 0,58 & 0,91 & 0,97 \\
CV (\%) & 5,31 & 7,33 & 7,61 & 6,99 & 16,44 \\
\hline
\end{tabular}

${ }^{(1)} \mathrm{L}$, linear; e Q, quadrática. * e **Significativo a 1 e $5 \%$ de probabilidade, respectivamente.

Tabela 6. Análise econômica dos diferentes níveis de caldo de cana desidratado para codornas europeias aos 42 dias de idade.

\begin{tabular}{lcccc}
\hline Variáveis $^{(1)}$ & \multicolumn{4}{c}{ Níveis de caldo de cana desidratado (\%) } \\
\cline { 2 - 5 } & 0 & 1,5 & 3,0 & 4,5 \\
\hline CAL (R \$ por tratamento) & 10,06 & 10,72 & 10,99 & 11,54 \\
PCP (kg por tratamento) & 11,99 & 11,97 & 11,87 & 11,72 \\
CCP (R\$ kg $\left.{ }^{-1}\right)$ & 0,84 & 0,90 & 0,93 & 0,98 \\
RB (R\$) & 223,15 & 222,81 & 220,95 & 218,17 \\
MB (R \$) & 213,10 & 212,09 & 209,96 & 206,63 \\
MBR (\%) & 100,00 & 99,53 & 98,53 & 96,97 \\
\hline
\end{tabular}

${ }^{(1)} \mathrm{CAL}$, custo de alimentação; PCP, peso da codorna produzida; CCP, custo da codorna produzida; $\mathrm{RB}$, renda bruta; $\mathrm{MB}$, margem bruta; e MBR, margem bruta relativa.

\section{Conclusões}

1. A ração com $4,5 \%$ de caldo de cana desidratado não prejudica o desempenho das codornas de corte (Coturnix coturnix), no período de 22 a 42 dias de idade.

2. Para a melhor qualidade de carcaça e peso de coxa e sobrecoxa de codornas, recomendam-se os níveis de $1,69,2,50$ e $2,34 \%$ de caldo de cana desidratado, respectivamente.

3. O nível de $1,5 \%$ de caldo de cana desidratado promove melhor índice econômico quando comparado aos níveis de 3,0 e 4,5\%.

4. O maior lucro ao produtor ocorre com a utilização da ração convencional, sem adição de caldo de cana desidratado.

\section{Agradecimentos}

Ao Conselho Nacional de desenvolvimento Científico e Tecnológico (CNPq) e à Fundação de apoio a pesquisa do Rio Grande do Norte (Fapern), pelo apoio financeiro e bolsas concedidas; à aluna Evelyn Rayssa Costa e Silva (in memoriam), pela colaboração na pesquisa.

\section{Referências}

BRASIL. Lei $\mathrm{n}^{\circ} 11.794$, de 8 de outubro de 2008. Regulamenta o inciso VII do $\S 1$ o do art. 225 da Constituição Federal, estabelecendo procedimentos para o uso científico de animais; revoga a Lei no 6.638 , de 8 de maio de 1979; e dá outras providências. Diário Oficial [da] República Federativa do Brasil, Poder Executivo, Brasília, DF, 9 out. 2008. Seção 1, p.1.

CABRAL, C.P. Tecnologia mais limpa para produção de mel seco de cana e sua inclusão em rações de frangos de corte. 2006. 112p. Tese (Doutorado) - Universidade Federal do Rio Grande do Norte, Natal.

COMPANHIA NACIONAL DE ABASTECIMENTO. PGPM: política de garantia de preços mínimos. [Brasília], 2013. Disponível em: <http://consultaweb.conab.gov.br/consultas/consultaPgpm. do?method=acaoListarConsulta $>$. Acesso em: 25 out. 2014.

CORDEIRO, M.D.; SOARES, R. da T.R.N.; FONSECA, J.B.; ÁVILA, R.P. de; MERCADANTE, M.B. Utilização do açúcar de cana (Saccharum officinarum) como fonte de energia para frangos de corte no período de 1 a 21 dias. Revista Brasileira de Zootecnia, v.32, p.903-908, 2003. DOI: 10.1590/ S1516-35982003000400016.

GUIDONI, A.L. Alternativas para comparar tratamentos envolvendo o desempenho nutricional animal. 1994. 105p. Tese (Doutorado) - Escola Superior de Agricultura Luiz de Queiroz, Piracicaba. 
LONGO, F.A.; MENTEN, J.F.M.; PEDROSO, A.A.; FIGUEIREDO, A.N.; RACANICCI, A.M.C.; GAIOTTO, J.B.; SORBARA, J.O.B. Diferentes fontes de proteína na dieta pré-inicial de frangos de corte. Revista Brasileira de Zootecnia, v.34, p.112-122, 2005. DOI: 10.1590/S1516-35982005000100015.

MARQUES, G.M.R. Secagem de caldo de cana em leito de espuma e avaliação sensorial do produto. 2009. 84p. Dissertação (Mestrado) - Universidade Estadual do Sudoeste da Bahia, Itapetinga.

MENDONÇA, M. de O.; SAKOMURA, N.K.; SANTOS, F.R. dos; BARBOSA, N.A.A.; FERNANDES, J.B.K.; FREITAS, E.R. Níveis de energia metabolizável e relações energia:proteína para aves de corte de crescimento lento criadas em sistema semiconfinado. Acta Scientiarum. Animal Sciences, v.29, p.23-30, 2007. DOI: 10.4025/actascianimsci.v29i1.248.

ROSTAGNO, H.S. (Ed.). Tabelas brasileiras para aves e suínos: composição de alimentos e exigências nutricionais. 3.ed. Viçosa: Ed. da UFV, 2011. 252p.

SILVA, J.H.V. da; COSTA, F.G.P. Tabelas para codornas japonesas e européias: tópicos especiais, composição de alimentos e exigências nutricionais. 2.ed. Jaboticabal: Funep, 2009. 107p.

SILVA, D.J. Análise de alimentos: métodos químicos e biológicos. 2.ed. Viçosa: Ed. da UFV, 1998. 165p.

TEIXEIRA, E.N.M.; SILVA, J.H.V.; BARROS, L.R. Valor nutritivo do ovo desidratado e do caldo de cana para pintos. Revista Brasileira de Ciências e Tecnologia Avícola, v.7, p.130, 2005. Suplemento 1.

TON, A.P.S.; FURLAN, A.C.; MARTINS, E.N.; TOLEDO, J.B.; SCHERER, C.; CONTI, A.C.M. Exigências de lisina digestível e de energia metabolizável para codornas de corte em crescimento. Revista Brasileira de Zootecnia, v.40, p.593-601, 2011. DOI: 10.1590/S1516-35982011000300018.

UNIÃO DA INDÚSTRIA DE CANA-DE-AÇÚCAR. Preço médio pago para cana-de-açúcar entregue pelos fornecedores no Estado de São Paulo. [2013]. Safra 2012/2013. Disponível em: $<$ http://www.unicadata.com.br/listagem.php?idMn=61 $>$. Acesso em: 25 out. 2014.

Recebido em 27 de julho de 2015 e aprovado em 3 de dezembro de 2015 